\title{
PERANCANGAN BANGUN ALAT MONITORING NOTIFIKASI TEGANGAN GENSET BERBASIS INTERNET OF THINGS DAN SMS GATEWAY
}

\author{
Muhammad Safii ${ }^{1)}$ dan Vidy ${ }^{2)}$ \\ ${ }^{1}$ Program Studi Manajemen Informatika, Stmik Balikpapan \\ ${ }^{2}$ Program Studi Teknik Informatika, STMIK Balikpapan \\ 1,2Jl. Letjen ZA Maulani Rt. 35 No. 9 Balikpapan 76114 \\ E-mail : msafii@stmikbpn.ac.id ${ }^{1)}$, vidy@stmikbpn.ac.id ${ }^{2)}$
}

\begin{abstract}
ABSTRAK
Monitoring besaran listrik secara online perlu dilakukan untuk mengetahui kondisi real dari sebuah system tenaga listrik. Teknologi Internet of things (IoT) dimungkinkan untuk memantau secara langsung kondisi tersebut. Pemantauan harus memberikan informasi kompleks dengan konsep SMART (Specific, Measurable, Attainable, Relevant, Time-bound) yaitu spesifik, terukur, dapat dicapai, relevan, dan dalam rentang waktu. Sumber energi listrik persediaannya terbatas, seperti halnya minyak, batubara, air, nuklir dan lain sebagainya. Untuk itu, perlu dilakukan usaha agar hemat dan efisien dalam pemanfaatannya. Dalam implementasinya Suplai energi listrik sangat berperan penting pada perusahaan untuk operasional sehingga suplai energi listrik tidak boleh berhenti. Oleh karena itu perusahaan tersebut perlu menggunakan dua alat bantuback-up suplai utama STG yaitu UPS (Uninterruptible Power Supply) dan generator set (genset). Akan tetapi pada saat ini sistem monitoring catu daya genset yang ada hanya berupa lampu indikator pada panel genset, sehingga perlu dilakukan monitoring genset secara onsite. Prototype sistem yang dibuat terdiri dari komponen - komponen elektronik seperti sensor arus, sensor tegangan, rangkaian pengkondisian sinyal, Arduino UNO, dan Ethernet Shield serta IComSat v1.1 SIM900A GSM/GPRS. Masing-masing komponen diuji sebelum dirangkai menjadi sebuah system.
\end{abstract}

Kata Kunci: Genset, IoT, SMART, UPS, Arduino

\section{PENDAhUluAN}

Seiring dengan kemajuan teknologi di segala bidang, maka catu daya utama PLN (Perusahaan Listrik Negara) sangat berpengaruh terhadap penyedian energi listrik bagi layanan publik. Akan tetapi suplai daya utama yang berasal dari PLN (Perusahaan Listrik Negara) tidak selamanya kontinu dalam penyalurannya. Suatu saat pasti terjadi pemadaman total yang dapat disebabkan oleh gangguan pada sistem pembangkit, atau gangguan pada sistem transmisi dan sistem distribusi.

Sedangkan suplai energi listrik sangat berperan penting pada perusahaan dan gedung-gedung perkantoran, dikarekan adanya komponen-komponen elektronik yang membutuhkan daya listrik utuk tetap dapat bekerja, sehingga suplai energi listrik tidak boleh berhenti. Oleh karena itu maka dibutuhkan alat back-up suplai utama PLN. Biasanya setiap bangunan-bangunan perusahaan menggunakan dua alat bantu back-up suplai utama PLN yaitu UPS (Uninterruptible Power Supply) dan generator set (genset).

Sumber catu daya kelistrikan yang ada pada perusahaan atau bangunan perkantoran haruslah tersedia secara berkelanjutan. Umumnya bangunan perkantoran menggunakan sistem kontrol pemindah tegangan induk otomatis yaitu: ATS (Automatic Transfer Switch). ATS (Automatic Transfer Switch) adalah sebuah sistem control yang berfungsi untuk pemindah secara otomatis distribusi dari catu daya PLN ke genset. Sehingga apabila catu daya utama PLN mati maka genset tersebut yang menggantikan peranan dari catu daya PLN untuk mensuplai sumber daya listik ke bangunan perkantoran tersebut. Selanjutnya apabila catu daya PLN kembali normal, maka fungsi ATS secara otomatis memindahkan distribusi daya listrik dari genset ke catu daya PLN.

Pada saat ini sistem monitoring catu daya genset yang ada hanya berupa lampu indikator pada panel genset, sehingga perlu dilakukan monitoring secara onsite pada sistem monitoring tersebut. Melihat permasalah tersebut maka diperlukan sistem monitoring yang dapat mendeteksi status tegangan output pada genset. Sistem monitoring yang diperlukan adalah sistem monitoring yang dapat dilakukan dari jarak jauh untuk mengetahui status tegangan output pada genset tersebut secara real time. Selain itu operator genset juga akan mendapatkan notifikasi nilai output tegangan genset berupa sms. Sistem ini bertujuan untuk memudahkan operator/ pengguna mengetahui kondisi tegangan output pada genset tanpa harus melakukan monitoring genset secara onsite.

Internet of Things, atau dikenal juga dengan singkatan IoT, merupakan sebuah konsep yang bertujuan untuk memperluas manfaat dari konektivitas internet yang tersambung secara terusmenerus. Adapun kemampuan seperti berbagi data, remote control, dan sebagainya, termasuk juga pada benda di dunia nyata. Pada dasarnya, IoT mengacu pada benda yang dapat diidentifikasikan secara unik sebagai representasi fisik dalam struktur berbasis Internet. Istilah Internet of 
Things awalnya disarankan oleh Kevin Ashton pada tahun 1999 dan mulai terkenal melalui Auto-ID Center di MIT. Realtime monitoring dimaksudkan untuk pemantauan besaran listrik tiga fasa dalam waktu nyata yang bersifat online dengan teknologi IoT.

\section{RUANG LINGKUP}

Penelitian tentang Monitoring dengan teknik yang sama telah banyak dilakukan antara lain :

1. Rancang Bangun Alat Monitoring Arus dan Tegangan Berbasis Mikrokontroler dengan SMS Gateway, Afrizal Fitriandi, (2016)

2. Sistem Kontrol Dan Monitoring Genset Melalui Internet, M Wildan Firdaus , (2017),

3. Pengontrolan Genset Jarak Jauh Melalui Website Berbasis Mikrokontroller Arduino MEGA 256016AU, Siti Wetenriajeng Sidehabi, St. Nurhayati Jabir (2014)

Pada penelitian Afrizl fitriandi peneltian memcoba membandingkan antara hasil penelitian sebelumnya dengan penelitian yang akan dilakukan, diantaranya adalah proses monitoring arus dan tegangan, dilakukan dengan menggunakan sms gateway sedangkan yang akan di buat oleh peneliti adalah monitoring bias menggunakan internet dan sms gateway.

Selanjutnya pada penelitian $M$. Wildan firdaus Perbedaan antara hasil penelitian sebelumnya dengan penelitian yang akan dilakukan, diantaranya adalah proses monitoring yang dilakukan adalah memonitoring level tangki pada genset sedangkan penelitian yang akan di buat adalah memonitoring tegangan output genset berbasis internet.

Selanjutnya Siti Wetenriajeng Sidehabi, St terdapat perbedaan antara hasil penelitian sebelumnya dengan penelitian yang akan dilakukan, diantaranya adalah kegunaan sistem sebagai pengontrol menghidupkan dan mematikan genset via web dan notifikasi menggunakan via SMS, web dan LCD. Sedangkan penelitian yang akan dibuat adalah untuk memonitoring tegangan on/off pada genset dan juga memberikan status voltage pada tegangan genset via web browser client kepada operator/pengguna.

Dari tiga penelitian di atas dapat di lihat perbedaan penelitian yang akan dikerjakan tahun ini yaitu penelitian fokus membuat alat monitoring arus tegangan genset dengan berbagai macam output sebagai notofikasi informasi kepada operatorr tentang arus geset yang digunakan. Selain itu juga akan dilakukan upaya pencegahan bila output yang dihasilkan tegengan genset melebihi atau turun dari nlai yang di tentukan.

Adapun tujuan jangka panjang dari penelitian ini adalah Monitoring besaran tegangan output genset secara real time dan akurat sehingga dapat memberikan informasi notifikasi secara real time tentang kondisi nilai tegangan output genset saat kondisi naik ataupun saat kondisi turun dengan memanfaatkan sms Gateway yang mengirimkan pesan ke operator.

\section{BAHAN DAN METODE}

Berikut disajikan bahan kajian dan metode dalam penelitian ini

\subsection{Metodologi Penelitian}

Konsep metodologi penelitian yang dilakukan adalah melakukan pendekatan solusi berbasis tujuan (Studi literatur), identifikasi masalah dan motivasi, penentuan fokus dari penelitian, perancangan dan pengembangan solusi, pembuatan simulasi, pengujian, pembahasan, pengambilan kesimpulan. Pendekatan ini menggunakan konsep yang diperkenalkan oleh Ken Peffers, Tuure Tuunanen, Marcus A. Rothenberger, dan Samir Chatterjee pada jurnal berjudul "A Design Science Research Methodology for Information Systems Research". Bagan alir dapat dilihat pada gambar 1 tentang konsep metode Design Science Research (DSR)

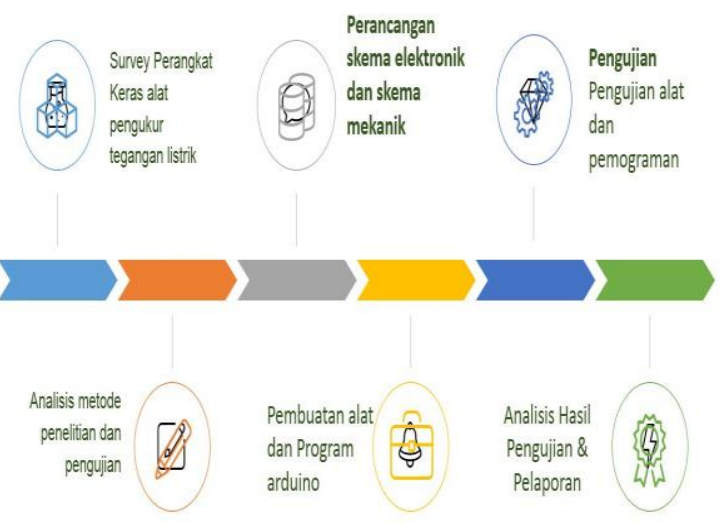

Gambar 1. Konsep metode penelitian

Berdasarkan konsep tersebut, metode penelitian yang disesuaikan dengan penelitian yang dilakukan memiliki tahapan studi literatur, identifikasi masalah dan motivasi, penentuan fokus dari survei alat, analisis metode penelitian dan pengujian, Perancangan, Pengujian, Analisis hasil pengujian dan pelaporan hasil penelitian. Penjabaran metode yang digunakan berdasarkan tahapan penelitian adalah sebagai berikut:

1. Analisi kebutuhan perangkat keras

Analisis dilakukan untuk mencari ketersediaan komponen-komponen apa saja yang di perlukan dalam penelitian.

2. Analisi metode perancangan dan pengujian Penentuan fokus ditentukan berdasarkan hasil identifikasi masalah dan motivasi yang mendorong dilakukannya penelitian. Pembuatan proposal dilakukan sebagai pedoman dalam melakukan penelitian.

3. Perancangan skema elektronik dan perancangan mekanik di buat berdasarkan fokus dari penelitian yang akan dikerjakan dengan metode 
pengembangan prototype. Untuk menunjang sistem monitoring ini digunakan mikroprosesor Arduino UNO sebagai aplikasi penunjang konsep IoT sekaligus sebagai pengendali, pengolah, dan pengirim data.

4. Pembuatan alat dan program arduino

Merangkai dang menghubungkan semua alat yang telah ditentukan sesuai dengan skema perangcangan.

5. Pengujian

Setelah rancangan dan demonstrasi/simulasi didapatkan, pengujian terhadap prototype dilakukan untuk dievaluasi sekaligus menilai pencapaian tujuan. Pengujian prototype yang dilakukan pada genset di Laboratorium STMIK Balikpapan untuk memonitor besaran output daya genset saat penggunaan full.

6. Analisis dan Pelaporan

Analisis dilakukan terhadap hasil pengujian yang didapatkan. Analisis bertujuan memberikan gambaran kondisi prototype dan masukan mengenai arah pengembangan lebih lanjut. Pelaporan Temuan Penelitian Laporan temuan penelitian berdasarkan data dan hasil analisis yang ada dibuat dan dilaporkan sebagai penelitian dosen pemula.

\subsection{Subjek dan Objek penelitian}

Subjek dalam penelitian ini adalah Alat monitoring dan notifikasi tegangan output genset berbasis IOT. Sedangkan objek dalam penelitian ini adalah salah satu genset cadangan STMIK Balikpapan yang saat ini telah di lembur menjadi satu oleh yayasan airlangga menjadi universitas mulia.

\subsection{Analisi Metode Pengumpulan Data}

Metode pengumpulan data merupakan teknik atau cara yang dilakukan untuk mengumpulkan data. Pada penelitian ini peneliti menggunakan metode pengumpulan data dengan cara:

1. Obrservasi merupakan teknik pengumpulan data dengan langsung terjun ke lapangan untuk mengamati permasalahan yang terjadi secara langsung di tempat kejadian secara sistematik kejadian-kejadian, perilaku, objek-objek yang dilihat dan hal-hal lain yang diperlukan dalam mendukung penelitian yang sedang berlangsung.

2. Wawancara merupakan teknik pengumpulan data yang dilakukan melalui tatap muka dan tanya jawab langsung antara pengumpul data terhadap narasumber/sumber data. Adapun sumber data peneliti yaitu para pegawai dan vendor genset tersebut.

3. Studi Literatur adalah salah satu metode pengumpulan data dengan cara membaca bukubuku dan jurnal sesuai dengan data yang dibutuhkan. Pada penelitian ini penulis memilih studi literatur untuk mengumpulkan referensi dari buku-buku mengenai mikrokontroler serta jurnal yang membahas tentang mikrokontroler.

\subsection{Diagram Blok Sistem}

Perancangan sistem monitoring arus dan tegangan yang akan dibuat dipresentasikan sesuai dengan blok diagram dan berdasarkan spesifikasi alat sebagai berikut:

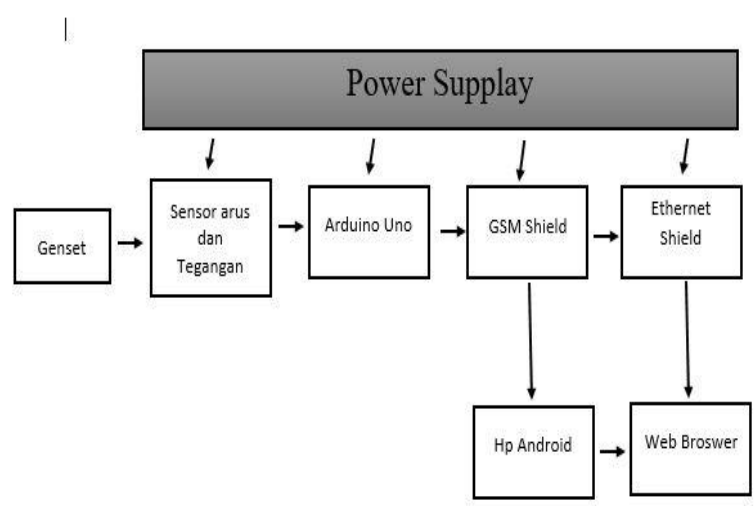

Gambar 2. Diagram Blok Sistem

Dalam perancangan dan pembuatan alat untuk memonitoring tegangan output genset diperlukan suatu sistem yang dapat memonitoring tegangan on/off genset dan juga dapat memonitoring voltage tegangan genset dari jarak jauh. Pembuatan alat dibedakan dalam beberapa blok fungsi gambaran umum mengenai sistem kerja dan pembagian blok sistem dari penelitian ini ditunjukkan pada gambar 2 .

\subsection{Perancangan Skema Blok arduino}

Pada tahap perancangan ini menggambarkan keseluruhan komponen elektronik yang di perlukan dalam membuat sebuat alat monitoring dan notifikasi tegangan genset dengan menggunakan IoT dan SMS Gateway. Penggunaan relay didalam rangkaian ini berfungsi sebagai piranti saklar yang dikontrol secara elektrik. Bila saklar mekanik biasa, seperti saklar lampu pada rumah, yang biasa kita tinggal tekan saja maka saklar akan on dan off. Beda dengan relay, yang tekan bukanlah tangan tetapi arus listrik yang mengaliri coil sehingga menimbulkan medan magnet yang akan menarik dan melepas sebuah plat/kontak dan membuat saklar on dan off. 


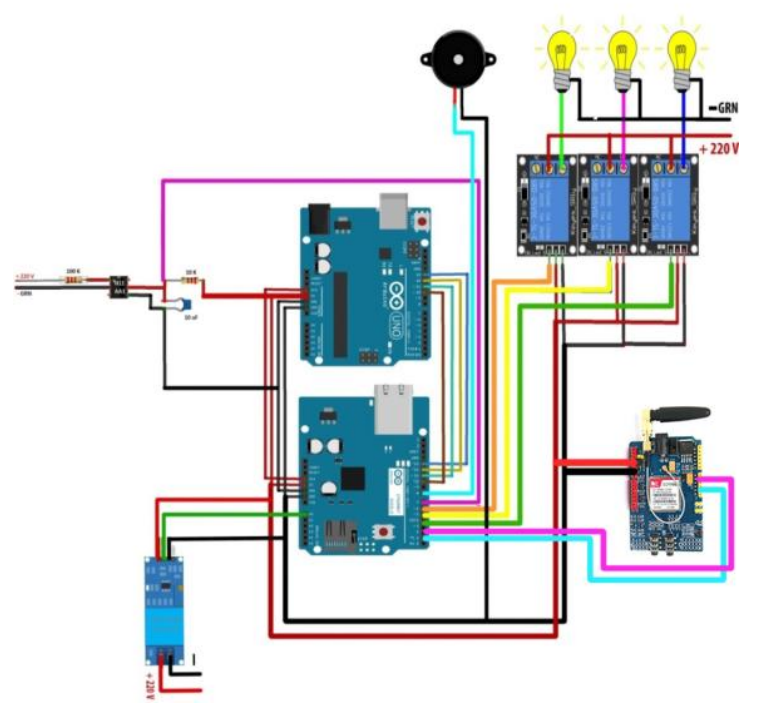

Gambar 3. Perancangan skema blok arduino

\subsection{Short Message Service (SMS)}

SMS merupakan fasilitas standar dari Global Sistem for Mobile Communication (GSM). SMS dapat dikirimkan melalui telepon selular hanya dalam beberapa detik selama berada pada jangkauan pelayanan GSM. Prinsip kerjanya adalah menyimpan dan menyampaikan pesan (store and forward). pesan tidak langsung dikirim ke penerima melainkan disimpan terlebih dahulu di SMS-Center (SMSC).

SMS center adalah program yang memiliki fungsi utama untuk mengatur distribusi data dan informasi dalam format dan aturan penulisan tertentu agar bisa memberikan output dan keluar informatif yang beragam sesuai dengan kategorinya. SMS gateway adalah sebuah sistem aplikasi yang digunakan untuk mengirim juga menerima SMS, dan biasanya digunakan pada aplikasi bisnis, baik untuk kepentingan broadcast promosi, servis informasi terhadap pengguna, penyebaran content produk / jasa dan lain lain. Gambaran mekanisme pengiriman SMS ini dapat dilihat pada gambar 4:

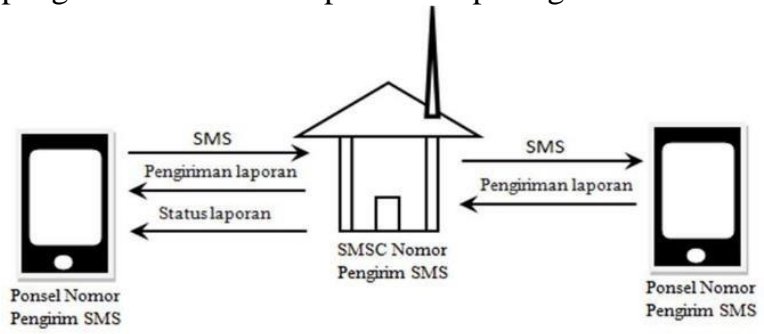

Gambar 4. Block Diagram SMS Dalam Satu Operator
Dari gambar 4 SMS yang dikirimkan oleh nomor pengirim akan dimasukkan terlebih dahulu ke dalam SMSC operator nomor pengirim, kemudian SMSC tersebut akan mengirimkan ke nomor yang dituju secara langsung. Nomor penerima kemudian akan mengirimkan sebuah deliveryreport yang menyatakan bahwa SMS telah diterima ke SMSC. SMSC kemudian meneruskan report tersebut ke nomor pengirim SMS, disertai status report dari proses pengiriman SMS tersebut. b. InterOperator SMS. Pada mekanisme ini, SMS yang dikirimkan akan melalui dua buah SMSC. Dapat dilihat pada gambar 5 .

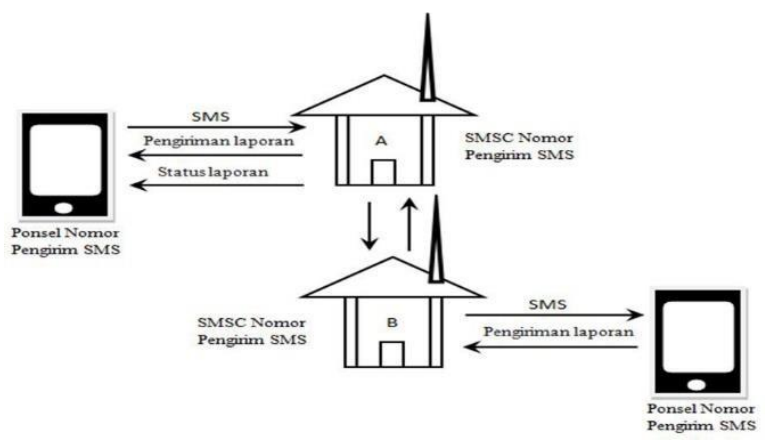

\section{Gambar 5. Block Diagram SMS Antar Operator yang Berbeda}

Pada gambar 5 selain masuk ke SMSC operator pengirim, SMS yang dikirimkan akan diteruskan oleh SMSC operator pengirim, ke SMSC operator penerima SMS, kemudian baru diteruskan ke nomor tujuan. Deliveryreport yang dihasilkan pun akan melalui jalur tersebut, agar dapat sampai ke nomor pengirim SMS. Dalam mekanisme ini, terlihat ada sebuah komunikasi tidak langsung antara dua operator berbeda. Komunikasi tersebut dapat berjalan, setelah terjadi sebuah kesepakatan kerja sama antar operator tersebut. Tidak adanya sebuah kesepakatan kerja sama antar operator, dapat menyebabkan SMS yang dikirimkan ke nomor tujuan dengan operator berbeda, tidak sampai pada nomor tujuan tersebut.

\section{PEMBAHASAN}

Berikut disajikan pembahasan dari perangkat yang dibangun

\subsection{Realisasi Alat Monitoring}

Seperti pada gambar 5 dibawah ini akan di jelaskan realisasi alat monitoring tegangan genset menggunakan iot dan sms gateway berbasis arduino. 


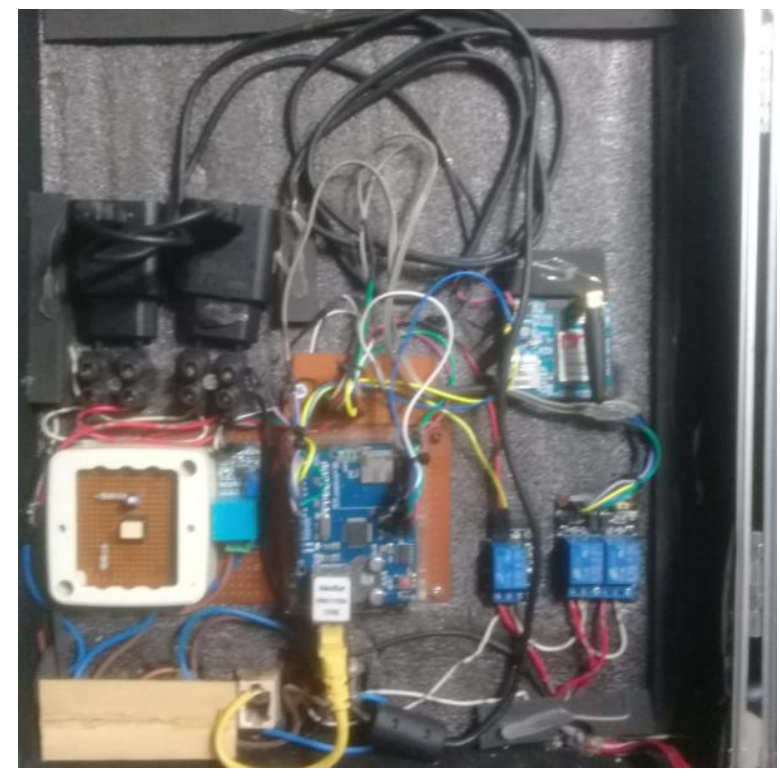

\section{Gambar 6. Realisasi Alat Monitoring Tegangan} Genset

\subsection{Realisasi Alat Etherned Shield}

Perangkat IOT digunakan Agar suatu perangkat dapat terhubung dalam jaringan internet. Penambahan ethernet shield dimaksudkan agar monitoring tegangan output genset dapat dipantau melalui komputer kapan pun dan dimanapun asalkan area masih terjangkau oleh jaringan LAN. Pada rangkaian ethernet shield dengan arduino dilakukan dengan menempatkan kaki - kaki keduanya sesuai shieldnya, setelah itu memprogram arduino uno dengan arduino IDE dan menguhungkan ethernet shield dengan modem mengunakan kabel LAN. Seperti gambar 7 dibawah ini ketika ethernet shield merespon IP internet yang dibaca dengan menunjukan lampu indikator menyala.

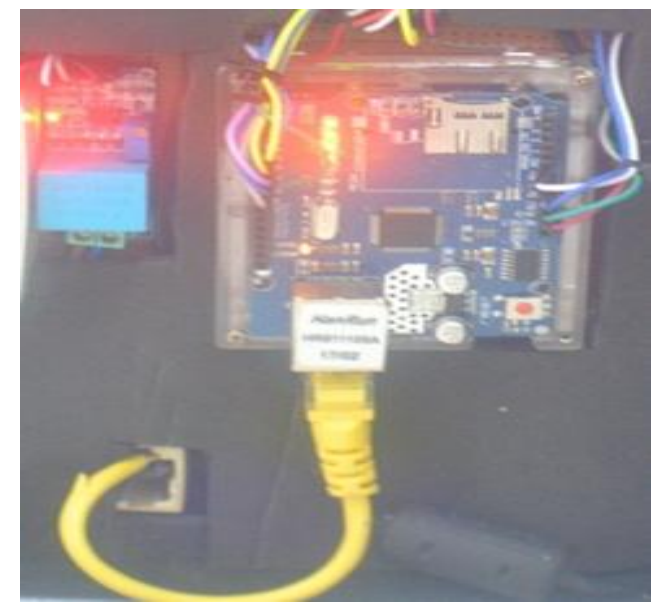

Gambar 7. Ethernet Shield Ketika Merespon IP Internet

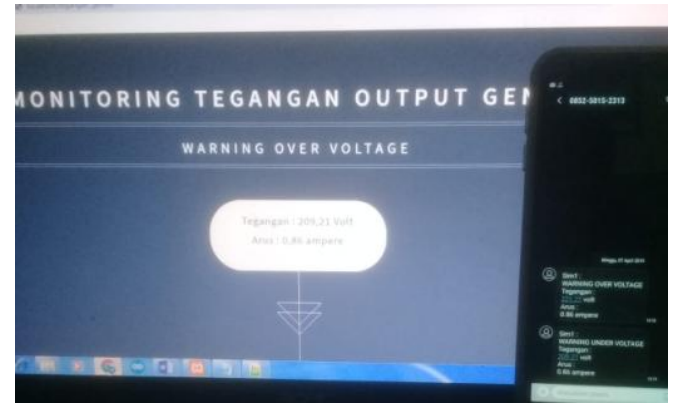

Gambar 8. Tampilan Monitoring Tegangan Genset Over Voltage di web browser

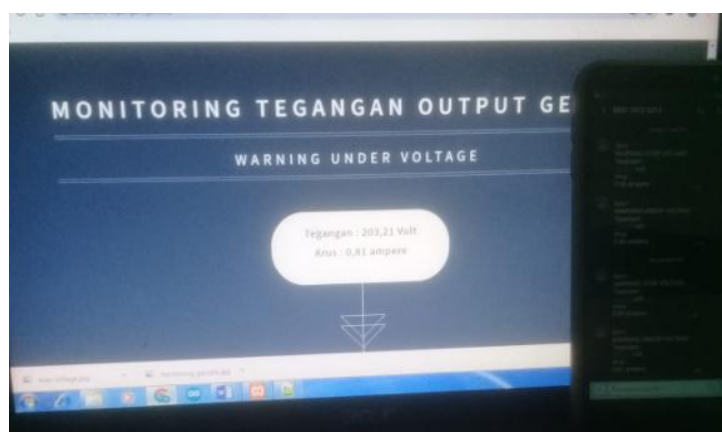

Gambar 9. Tampilan Monitoring Tegangan Genset Undervoltage di web browser

\subsection{Realisasi Alat IComSat GSM GPRS}

IComSat merupakan suatu modul yang digunakan untuk arduino, yaitu modul SIM900A quad-band GSM/GPRS.IComSat dikontrol dengan menggunakan AT commands dan kompatibel dengan Arduino / Iteaduino dan Mega.

IComSat GSM GPRS SIM900A digunakan sebagai notifikasi yang dapat mengirimkan SMS ketika alat mendeteksi under voltage dan over voltage. Pengujian dilakukan dengan menghubungkan Modul IComSat SIM900A GSM GPRS dengan arduino uno, selanjutnya pengujian dengan memberikan respon pada modul sensor ZMPT101B untuk menginformasikan SMS ke handphone.

Pada gambar 9 menunjukan kondisi ketika Modul IComSat SIM900A GSM GPRS aktif dan mengirimkan SMS "Warning Over Voltage" Atau "Warning Under Voltage " dengan di ikutkan besaran nilai voltage yang di baca oleh sensor tegangan. 


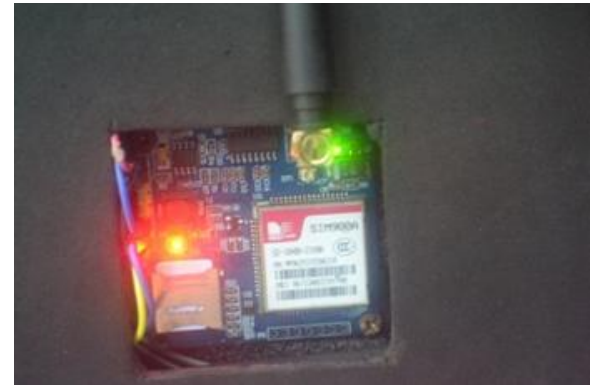

Gambar 10. IComSat SIM900A GSM GPRS aktif

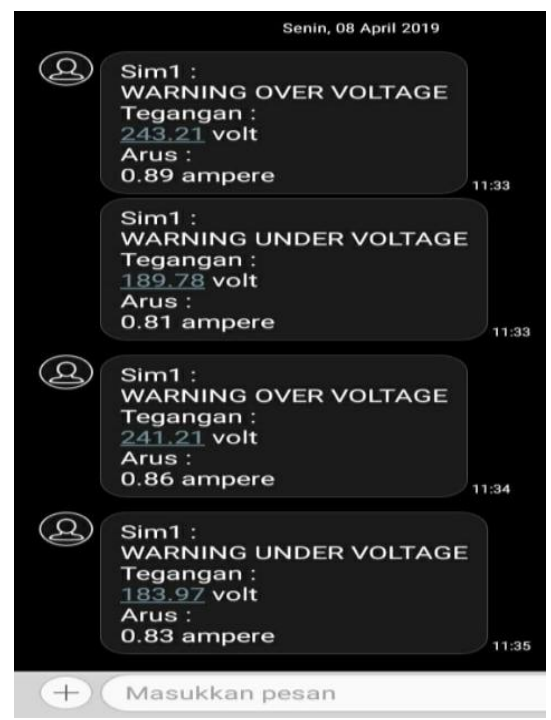

Gambar 11. Format SMS Gateway Monitoring tegangan

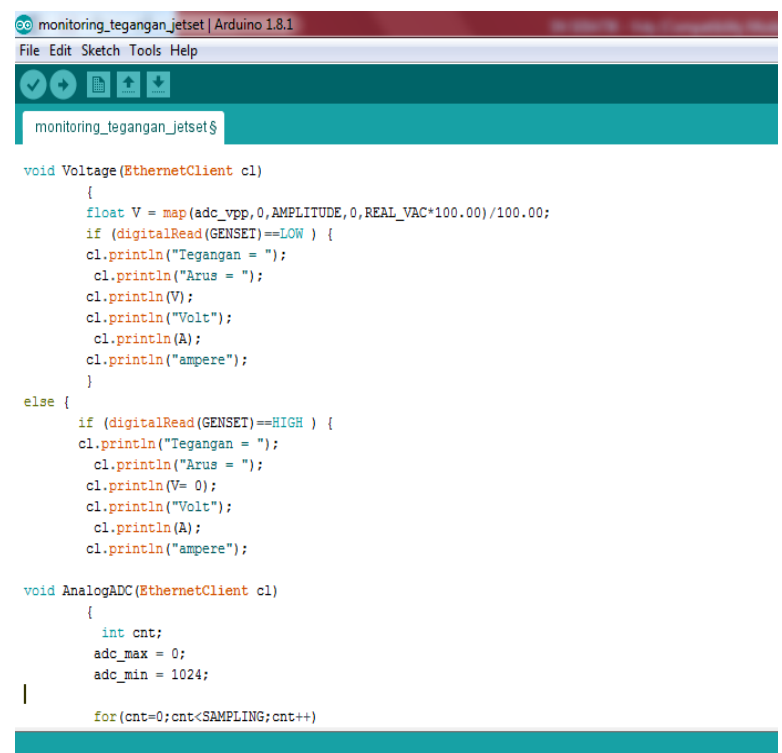

Gambar 12. Script Arduino IDE Ethernet Shield
Pada gambar 11 menjelaskan tentang fungsi coding ketika optocoupler H11AA1 mendapatkan catu daya input, maka sensor ZMPT101B akan mendeteksi tegangan dan memberikan status voltage pada halaman web browser. Dan apabila optocoupler H11AA1 tidak mendapatkan catu daya input, maka sensor ZMPT101B tidak mendeteksi tegangan dan memberikan status voltage 0 pada halaman web browser.

Ketika sensor ZMPT101B mendeteksi tegangan lebih besar sama dengan 240 volt, maka akan memberikan status "WARNING OVER VOLTAGE " pada halaman web browser dan lampu indikator over voltage, buzzer akan hidup, dan modul SIM900A akan mengirimkan SMS dengan isi pesan "WARNING OVER VOLTAGE" ke no telepone yang sudah di input pada program.

\section{KESIMPULAN}

Sistem monitoring tegangan output genset mengunakan ethernet shield berbasis arduino uno ini diharapkan dapat mempermudah operator/pengguna untuk memonitoring tegangan output genset secara real time. Dalam proses pemrograman arduino uno menggunakan bahasa pemrograman $\mathrm{C}$ dengan software arduino IDE 1.8.5.

Cara kerja dari alat monitoring tersebut adalah, apabila sensor tegangan mendeteksi catu daya maka akan memberikan status kondisi genset (GENSET ON/OFF) dan akan menampilkan status voltage pada halaman web browser client. Apabila sensor tegangan mendeteksi voltage lebih kecil sama dengan $200 \mathrm{~V}$ maka lampu indikator under voltage akan hidup, buzzer akan hidup, dan modul SIM 900A akan mengirimkan SMS "Warning Under Voltage " ke nomor handphone yang telah diinputkan pada program dan apabila

\section{SARAN}

Sistem ini tentu saja masih belum sempurna. Masih banyak hal yang dapat dilakukan untuk mengembangkan sistem ini agar menjadi lebih baik lagi, diantaranya adalah:

1. Apabila sensor ZMPT101B mendeteksi under/over voltage alat bisa melakukan penanganan langsung seperti mematikan genset dengan menambahkan button control pada halaman web browser client atau dapat mematikan genset via SMS.

2. Untuk Tampilan web supaya bisa ditambahkan security dan sistem warning agar dapat mengingatkan operator maupun teknisi

3. Menambahkan database pada perangkat lunak, agar data-data yang terbaca pada sensor dapat disimpan pada database.

4. Prototype alat ini bisa digabungkan dengan penelitian sistem kontrol jarak jauh 


\section{DAFTAR PUSTAKA}

Z. Pei, L. Fangxing dan B. Navin , Next-Generation Monitoring, Analysis, and Control for the Future Smart Control Center, IEEE,

G. Korteum, F. kawsar, D. Fitton dan V. Sundramoorthy, Smart objects as building blocks for the internet of things. Internet Computing, New York: IEEE, 2012

Fitriandi, Afrizal, dkk.2016. Rancang Bangun Alat Monitoring Arus dan Tegangan Berbasis Mikrokontroler dengan SMS Gateway. Jurnal Rekayasa dan Teknologi Elektro. Volume 10, No. 2, Mei 2016

Firdaus, M Wildan, dkk. 2017. Sistem Kontrol dan Monitoring Genset Melalui Internet Control System and Monitoring Genset via Internet. Vol.4, No.1 April 2017 ,Page 36

Sidehabi,Sitti Wetenriajeng dan Nurhayati Jabir, 2015, Pengontrolan Genset Jarak Jauh Melalui Website Berbasis Mikrokontroller Arduino MEGA 256016AU.Seminar Nasional.Makassar

Jurnal Teknologi Informasi-Aiti, Vol. 5. No. 2. Agustus 2008: 101- 200
Syahwil, Muhammad., 2013, Panduan Mudah Simulasi dan Praktek Mikrokontroller Arduino, C.V Andi Offset, Yogyakarta.

K. Peffers, T. Tuunanen, M. A. Rothenberger dan S. Chatterjee, "A Design Science Research Methodology for Information Systems Research," Journal of Management Information Systems, vol. 24, no. 3, pp. 45-78, 2007

B. Susetyo, Statistika untuk Analisis Data Penelitian, Bandung: PT Refika Aditama, 2012.

Sulindawati, dan Fathoni, M. 2010. Pengantar Analisa Perancangan Sistem. Medan: STMIK Triguna Dharma. Vol. 9, No. 2.

\section{UCAPAN TERIMA KASIH}

Penelitian ini Dibiayai oleh

Direktorat Riset dan Pengabdian Masyarakat Direktorat Jenderal Penguatan Riset dan Pengembangan Kementerian Riset, Teknologi, dan Pendidikan Tinggi sesuai dengan Kontrak Penelitian Tahun Anggaran 2019 